\title{
Simultaneous dark fermentative hydrogen and ethanol production from waste bread in a mixed packed tank reactor
}

Wei Han, Yunyi Hu, Shiyi Li, Jingang Huang, Qiulin Nie, Hongting Zhao*, Junhong Tang*

College of Materials and Environmental Engineering, Hangzhou Dianzi University,

\author{
Hangzhou, 310018, China
}

\begin{abstract}
Simultaneous dark fermentative hydrogen and ethanol production from waste bread in a mixed packed tank reactor (MPTR) was investigated. Waste bread was first hydrolyzed by the produced enzymes to generate the waste bread hydrolysate which was subsequently introduced to the MPTR for dark fermentative hydrogen and ethanol production. The optimal hydrogen and ethanol production rates were $15.01 \mathrm{mmol} /(\mathrm{h} \cdot \mathrm{L})$ and $23.25 \mathrm{mmol} /(\mathrm{h} \cdot \mathrm{L})$ when the organic loading rate reached $32 \mathrm{~g} /(\mathrm{L} \cdot \mathrm{d})$. The unit hydrogen and ethanol production were $4.87 \mathrm{mmol}$ hydrogen/g waste bread and 7.54 mmol ethanol/g waste bread, respectively. This study provided a new direction for economic and efficient hydrogen and ethanol production from waste bread.
\end{abstract}

Keywords: waste bread; organic loading rate; hydrogen production; ethanol production

* Corresponding authors: Junhong Tang, Tel.: +86 13738020870, E-mail address: dr_tjh@163.com; Hongting Zhao, E-mail address: hzhao@ hdu.edu.cn 


\section{Introduction}

Because of the depletion of fossil fuels and environmental pollutions, research on biofuels production has attracted considerable attentions (Panagiotopoulos et al., 2015). Ethanol and hydrogen are considered to be the promising energy carriers since they are renewable and environmental-friendly (Lay et al., 2012). Dark fermentation is an attractive way for hydrogen and ethanol production because it can use organic raw materials as substrate (Chu et al., 2012; Urbaniec and Grabarczyk, 2009). Waste bread, which is an important part of municipal solid wastes, is reported to be 2.1 million tons per annum in China. It is considered to be a commercially available organic substrate because of cost-effective and high concentration of nutrients (Han et al., 2015; Urbaniec and Grabarczyk, 2014). However, nutrients stored in the waste bread are in the form of macromolecules (such as starch and protein) which have to be hydrolyzed into the utilizable forms, such as glucose and free amino nitrogen (FAN), for dark fermentative hydrogen and ethanol production (Panagiotopoulos et al., 2010). Enzymatic hydrolysis using glucoamylase and protease can efficiently facilitate this process (Hawkes et al., 2008). However, information about dark fermentative hydrogen and ethanol production from enzyme hydrolyzed waste bread is limited.

Therefore, the present study focused on continuous hydrogen and ethanol production 
in a mixed packed tank reactor (MPTR) using waste bread hydrolysate as substrate. This study gives a protocol to use high starch containing raw materials (such as waste bread) for dark fermentative hydrogen and ethanol production (Figure 1).

\section{Materials and methods}

\subsection{Microorganisms}

Aspergillus awamori and Aspergillus oryzae, which were utilized in solid state fermentation to produce glucoamylase and protease, were prepared as described in our previous study (Han et al., 2016a). The anaerobic sludge was collected from a local anaerobic wastewater treatment plant and heat pretreated in a water bath at $100{ }^{\circ} \mathrm{C}$ for 6 h.

\subsection{Enzymatic hydrolysis}

The waste bread was provided by the local Supermarket. Table 1 showed the composition of the waste bread which was analyzed according to procedures described in Han et al. (2015). The detailed procedures for glucoamylase and protease production from solid state fermentation by A. awamori and A.oryzae were provided in our previous study (Han et al., 2016b). The enzymatic hydrolysis was carried out in two 2.5 L bioreactors. The produced enzymes (glucoamylase and protease) were used to 
hydrolyze the waste bread $(10 \%, \mathrm{w} / \mathrm{v})$. The enzymatic hydrolysis of waste bread was operated at $55{ }^{\circ} \mathrm{C}$ throughout the experiment with agitation speed of $500 \mathrm{rpm}$.

\subsection{Mixed Packed Tank Reactor (MPTR)}

A $4 \mathrm{~L}$ mixed packed tank reactor (MPTR) with an effective volume of $2.6 \mathrm{~L}$ was used in this study. Porous glass beads were packed in the MPTR as support carrier for cell immobilization to reach a volume ratio of $10 \%(\mathrm{v} / \mathrm{v})$. The heat pretreated sludge was seeded in the MPTR with continuous mode from waste bread hydrolysate for $240 \mathrm{~h}$ at a HRT of $24 \mathrm{~h}$ for cell immobilization. Then, the MPTR was also operated in continuous mode for simultaneous hydrogen and ethanol production at temperature of $35 \pm 1{ }^{\circ} \mathrm{C}$ and HRT of $6 \mathrm{~h}$ (Ren et al., 2006). In order to investigate the effect of organic loading rate (OLR) on hydrogen and ethanol productions, the waste bread hydrolysate was diluted to certain OLR $(8-32 \mathrm{~g} /(\mathrm{L} \cdot \mathrm{d}))$ by distilled water. Fermentation $\mathrm{pH}$ was controlled above 4 using $5 \mathrm{M} \mathrm{NaOH}$ solution. The MPTR was mixed at an agitation rate of $80-100 \mathrm{rpm}$ by an agitator to maintain a well mixing and to facilitate rapid release of hydrogen from liquid phase.

\subsection{Analytical Methods}

The glucose and FAN, which were produced in the waste bread hydrolysate, were measured according to our previous study (Han et al., 2016b). Chemical oxygen 
demand (COD) was monitored and measured daily according to Standard Methods

(APHA, 1995). Biogas was analyzed using a gas chromatography (SC-7, Shandong Lunan Instrument Factory). Detection of soluble microbial products (SMPs) was analyzed by another gas chromatograph (GC112, Shanghai Anal. Inst. Co.). The detailed procedures for biogas and SMPs were described in our previous study (Han et al., 2015).

\section{Results and discussion}

\subsection{Enzymatic hydrolysis of waste bread}

The produced enzymes (glucoamylase and protease) via SSF were used to hydrolyze the waste bread $(10 \%, w / v)$. The yield of glucose and FAN from the waste bread hydrolysis was shown in Figure 2 (a) and (b), respectively. It was observed that both glucose and FAN increased with time and reached the saturation concentrations within $24 \mathrm{~h}$. The final glucose and FAN concentration derived from the waste bread hydrolysate were $40.58 \mathrm{~g} / \mathrm{L}$ and $509.68 \mathrm{mg} / \mathrm{L}$, respectively.

\subsection{Continuous fermentative hydrogen and ethanol production}

\subsubsection{Hydrogen and ethanol production}

Figure 3 indicated the performance of hydrogen and ethanol production rates in the 
MPTR at different OLRs $(8-32 \mathrm{~g} /(\mathrm{L} \cdot \mathrm{d}))$. The hydrogen and ethanol production rates initially increased with an increase of OLR and the highest hydrogen and ethanol production rate of $15.01 \mathrm{mmol} /(\mathrm{h} \cdot \mathrm{L})$ and $23.25 \mathrm{mmol} /(\mathrm{h} \cdot \mathrm{L})$ were obtained when OLR was $32 \mathrm{~g} /(\mathrm{L} \cdot \mathrm{d})$. However, the hydrogen and ethanol production rates slightly decreased to $13.5 \mathrm{mmol} /(\mathrm{h} \cdot \mathrm{L})$ and $20.95 \mathrm{mmol} /(\mathrm{h} \cdot \mathrm{L})$ when OLR further increased to $40 \mathrm{~g} /(\mathrm{L} \cdot \mathrm{d})$. It was concluded that using higher OLR could lead to a higher hydrogen and ethanol production rate, but much more OLR would result in inhibition of hydrogen and ethanol production activity.

\subsubsection{Composition of soluble microbial products (SMPs)}

As shown in Table 2, the formation of SMP tended to increase as OLR increased from 8 to $32 \mathrm{~g} /(\mathrm{L} \cdot \mathrm{d})$. The SMP decreased slightly when the OLR further increased to $40 \mathrm{~g} /(\mathrm{L} \cdot \mathrm{d})$. The major product was ethanol which accounted for $40.9 \%-49.4 \%$ of the total SMP regardless of different OLRs. This composition of SMP indicated that the culture environment was favorable for hydrogen production because ethanol was the predominant product in most efficient hydrogen-producing system (Ren et al., 2006). However, it was interesting to find that the hydrogen-producing system still kept ethanol-type fermentation, even though the hydrogen production rate decreased slightly when the OLR reached $40 \mathrm{~g} /(\mathrm{L} \cdot \mathrm{d})$. This could be due to an overload of OLR causing a 
substrate inhibition on hydrogen producer, which was consistent with Singh's results (2013). Linear regression results (Figure 4) show that the correlation between ethanol production rate (y) and hydrogen production rate (x) can be expressed as:

$$
y=1.6012 x-1.7021\left(R^{2}=0.9311\right)
$$

The ethanol-type fermentation can produce ethanol and acetate. Also, it can preserve the balance between $\mathrm{NADH}$ and $\mathrm{NAD}^{+}$. Ethanol is the main product of this type fermentation. Thus, it will diminish the production of acids (e.g. acetate, butyrate) and perform hydrogen production smoothly and swiftly. The ethanol/acetate ratio has been used as an indicator of hydrogen production in acidogenesis system (Ren et al., 2006). In general, a higher ethanol/acetate ratio gave a higher hydrogen production. In this study, the ethanol/acetate ratio increased from 1.02 to 1.31 when the OLR increased from 8 to $32 \mathrm{~g} /(\mathrm{L} \cdot \mathrm{d})$. However, the ratio slightly decreased to 1.29 when OLR further increased to $40 \mathrm{~g} /(\mathrm{L} \cdot \mathrm{d})$ (Table 2$)$.

It was observed that the optimal OLR obtained from this study was $32 \mathrm{~g} /(\mathrm{L} \cdot \mathrm{d})$, the theoretical glucose value of $30 \mathrm{~g}$ glucose/(L·d) could be calculated. As the working volume of the MPTR was $2.6 \mathrm{~L}$, it could be calculated that $78 \mathrm{~g}$ glucose $(192.22 \mathrm{~g}$ waste bread) was consumed per day. The maximum hydrogen and ethanol production rate $(\mathrm{OLR}=32 \mathrm{~g} /(\mathrm{L} \cdot \mathrm{d}))$ were $15.01 \mathrm{mmol} /(\mathrm{h} \cdot \mathrm{L})$ and $23.25 \mathrm{mmol} /(\mathrm{h} \cdot \mathrm{L})$ which were 
equivalent to $936.6 \mathrm{mmol}$ hydrogen/day and $1450.8 \mathrm{mmol}$ ethanol/day, respectively.

Therefore, the unit hydrogen and ethanol production were $4.87 \mathrm{mmol}$ hydrogen/g waste bread and $7.54 \mathrm{mmol}$ ethanol/g waste bread, respectively. To our knowledge, this is the first study which reports the unit hydrogen and ethanol production from waste bread.

\section{Conclusions}

This study demonstrated the feasibility of fermentative hydrogen and ethanol production from waste bread hydrolysate in a mixed packed tank reactor (MPTR). The crude enzymes, which were generated by fungi via solid-state fermentation, could be used to hydrolyze the waste bread. The resulting hydrolysates could be used for hydrogen and ethanol production with the highest hydrogen and ethanol production rates of $15.01 \mathrm{mmol} /(\mathrm{h} \cdot \mathrm{L})$ and $23.25 \mathrm{mmol} /(\mathrm{h} \cdot \mathrm{L})$. This study offered a potential economic and efficient bioprocess for hydrogen and ethanol production from waste bread.

\section{Acknowledgements}

This research was supported by Zhejiang Education Department (Y201533249) and 
National Science Foundation of China (No. 51408171 and No. 41373121).

\section{References}

APHA. Standard Methods for the Examination of Water and Wastewater. American Public Health Association, Washington, DC. 1995.

Chu, C.Y.; Sen, B.; Lay, C.H.; Lin, C.Y. Direct fermentation of sweet potato to produce maximal hydrogen and ethanol. Appl. Energy 2012, 100, 10-18.

Han, W.; Ye, M.; Zhu, A.J.; Zhao, H.T.; Li, Y.F. Batch dark fermentation from enzymatic hydrolyzed food waste for hydrogen production. Bioresour. Technol. 2015, 191, 24-29.

Han, W.; Hu, Y.Y.; Li, S.Y.; Li, F.F.; Tang, J.H. Biohydrogen production in the suspended and attached microbial growth systems from waste pastry hydrolysate. Bioresour. Technol. 2016a, 218, 589-594.

Han, W.; Ye, M.; Zhao, H.T.; Li, Y.F. A combined bioprocess based on solid-state fermentation for dark fermentative hydrogen production from food waste. J. Cleaner Prod. 2016b, 112, 3744-3749.

Hawkes, F.R.; Forsey, H.; Premier, G.C.; Auty, D. Fermentative production of hydrogen from a wheat flour industry co-product. Bioresour. Technol. 2008, 99, 5020-5029. 
Lay, C.H.; Lin, H.C.; Lin, C.Y. Simultaneous hydrogen and ethanol production from sweet potato via dark fermentation. J. Cleaner Prod. 2012, 27, 155-164.

Panagiotopoulos, I.A.; Karaoglanoglou, L.S.; Claassen, P.A.M.; Koukios, E. Technical suitability mapping of feedstocks for biological hydrogen production. J. Cleaner Prod. 2015, 102, 521-528.

Panagiotopoulos, J.; Bakker, R.; de Vrijie, T.; Urbaniec, K.; Claassen, P.A.M. Prospects of utilization of sugar beet carbohydrates for biological hydrogen production in the EU. J. Cleaner Prod. 2010, 18, 9-14.

Ren, N.Q.; Li, J.Z.; Li, B.K. Biohydrogen production from molasses by anaerobic fermentation with a pilot-scale bioreactor system. Int. J. Hydrogen Energy 2006, $31,2147-2157$.

Singh, L.; Siddiqui, M.F.; Ahmad, A. Biohydrogen production from palm oil mill effluent using immobilized mixed culture. J. Ind. Eng. Chem. 2013, 19, 659-664.

Urbaniec, K.; Grabarczyk, R. Raw materials for fermentative hydrogen production. J. Cleaner Prod. 2009, 17, 959-962.

Urbaniec, K.; Grabarczyk, R. Hydrogen production from sugar beet molasses - a techno-economic study. J. Cleaner Prod. 2014, 65, 324-329. 


\section{Figure captions}

Table 1 Composition of waste bread used in this study (mass per $100 \mathrm{~g}$ ).

Table 2 Composition of soluble microbial products at different OLRs.

Figure 1 Schematic diagram of the proposed biological hydrogen and ethanol production from waste bread.

Figure 2 Glucose (a) and FAN (b) production from enzymatic hydrolysis of waste bread.

Figure 3 Performance of hydrogen and ethanol production rates at different OLRs.

Figure 4 Correlation of hydrogen and ethanol production rates in the MPTR. 
Table 1 Composition of waste bread used in this study (mass per $100 \mathrm{~g}$ ).

\begin{tabular}{cccc}
\hline Component & Value $(\mathrm{g})$ & Component & Value $(\mathrm{g})$ \\
\hline Moisture & $24.3 \pm 0.8$ & Starch & $44.6 \pm 1.5$ \\
Protein & $15 \pm 1.2$ & Phosphorus & $0.08 \pm 0.01$ \\
Total organic & $1.5 \pm 0.1$ & Ash & $2.3 \pm 0.2$ \\
nitrogen & & & \\
\hline
\end{tabular}


Table 2 Composition of soluble microbial products at different OLRs.

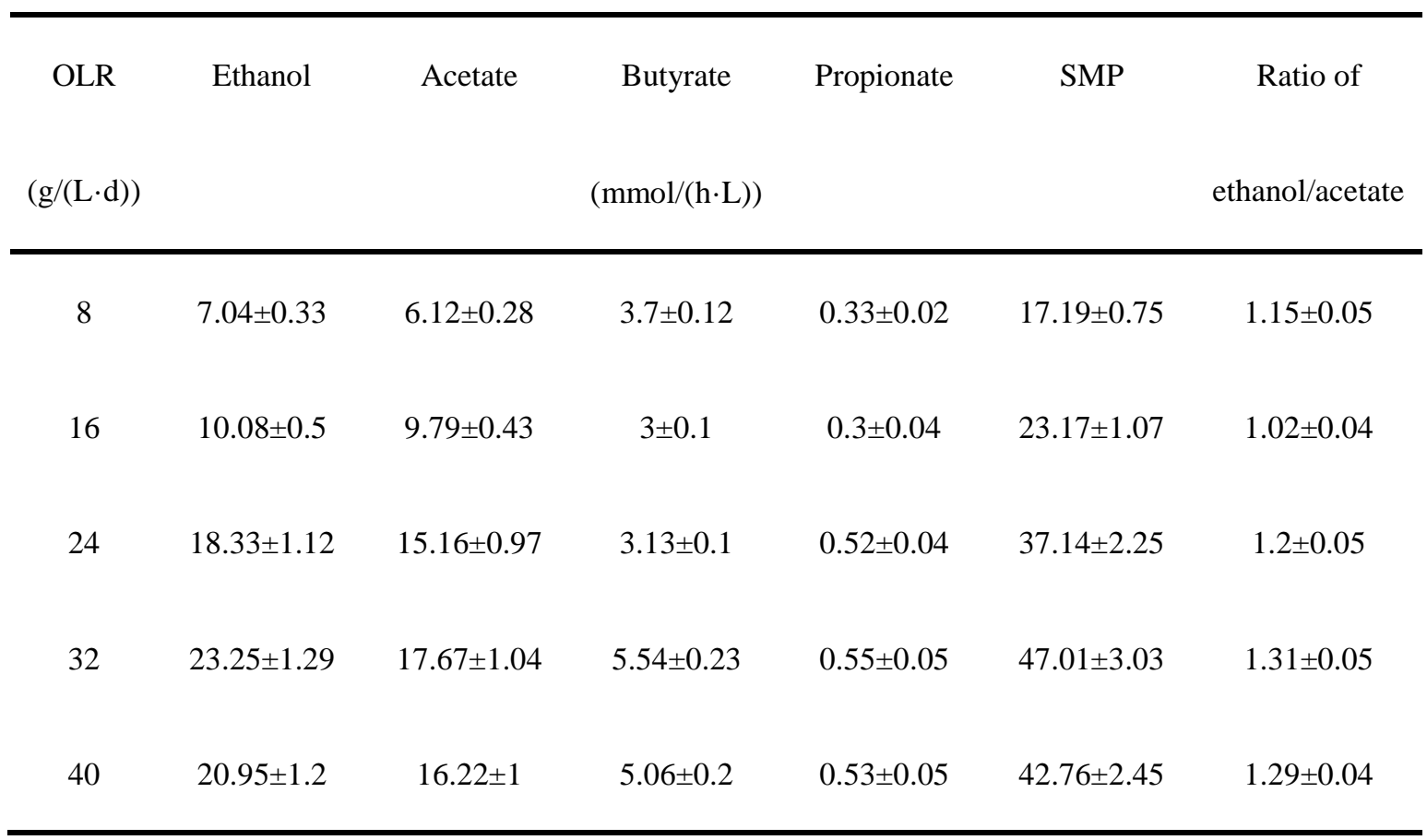




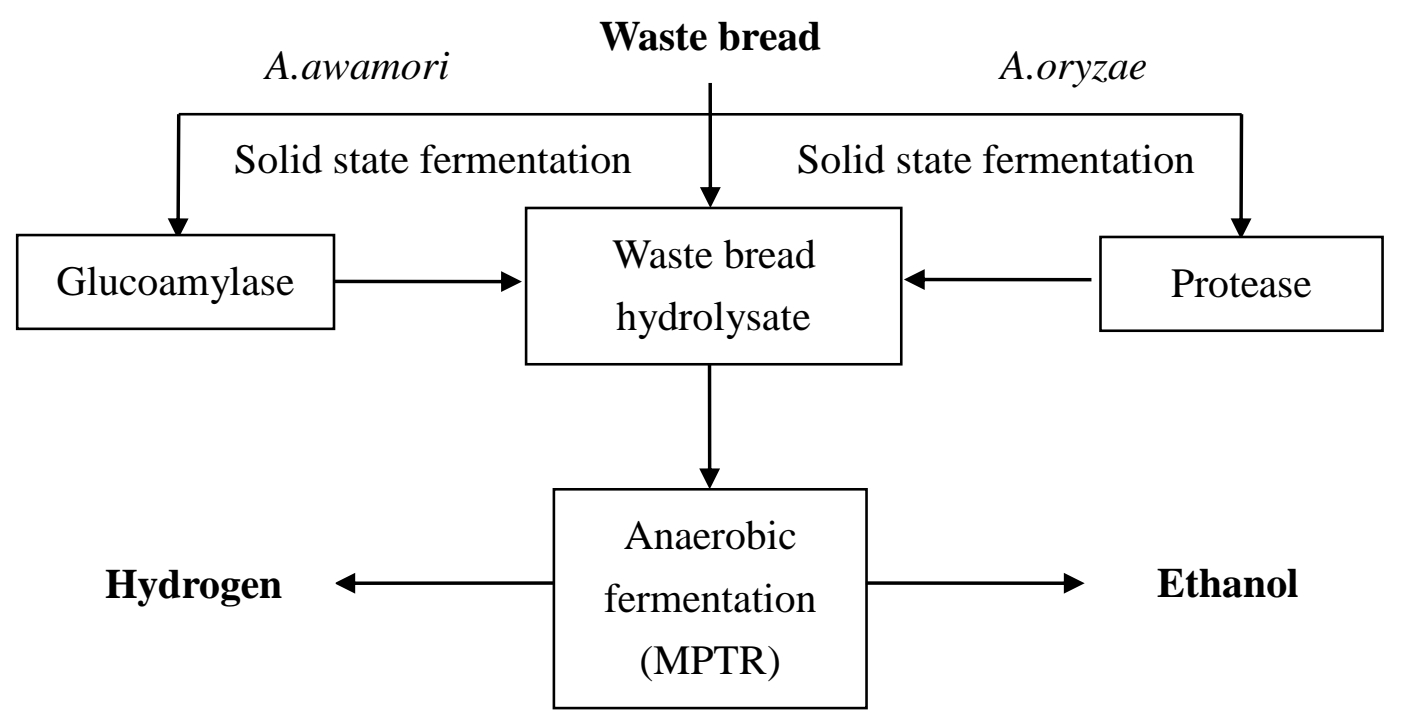

Figure 1 Schematic diagram of the proposed biological hydrogen and ethanol

production from waste bread. 

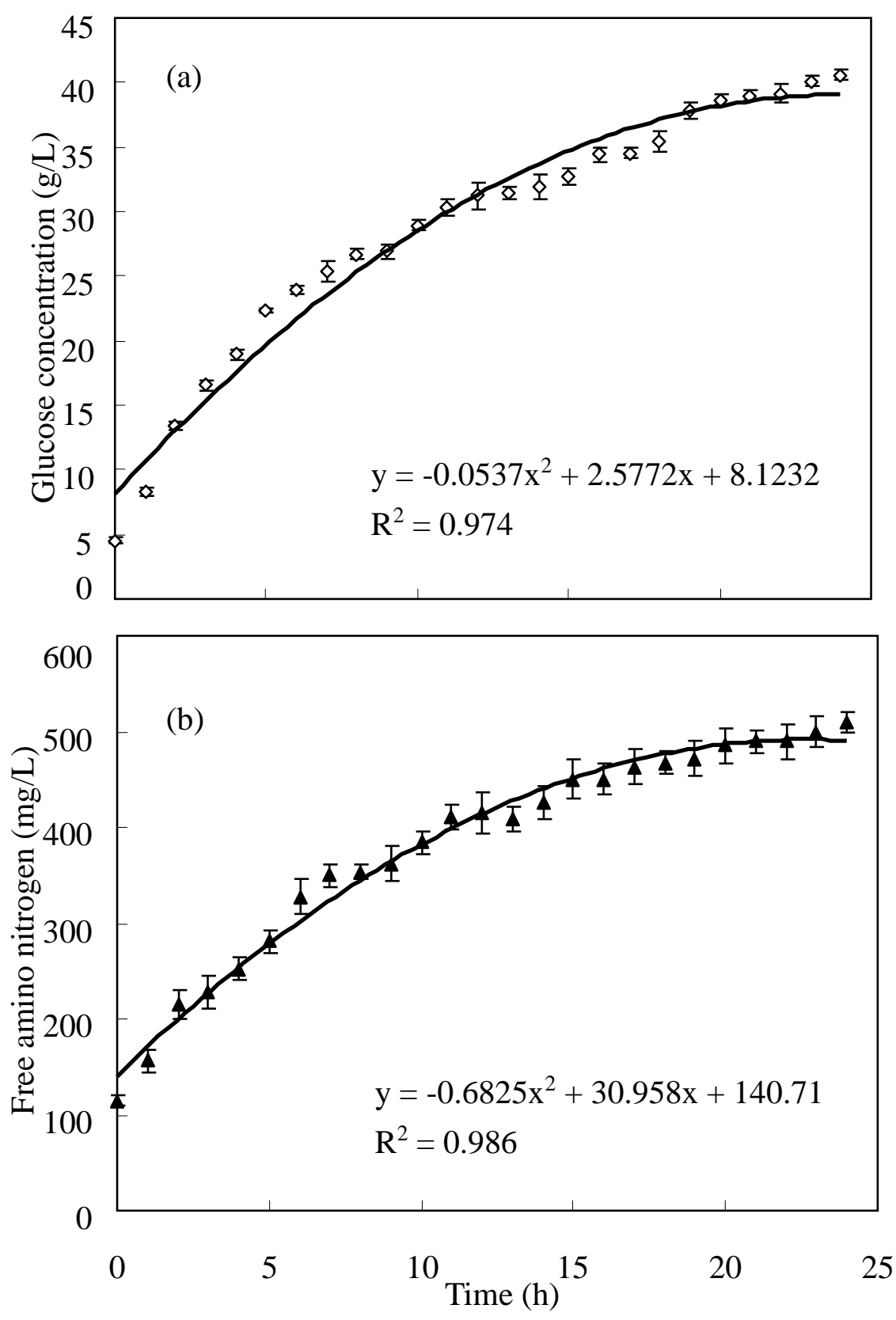

Figure 2 Glucose (a) and FAN (b) production from enzymatic hydrolysis of waste bread. 


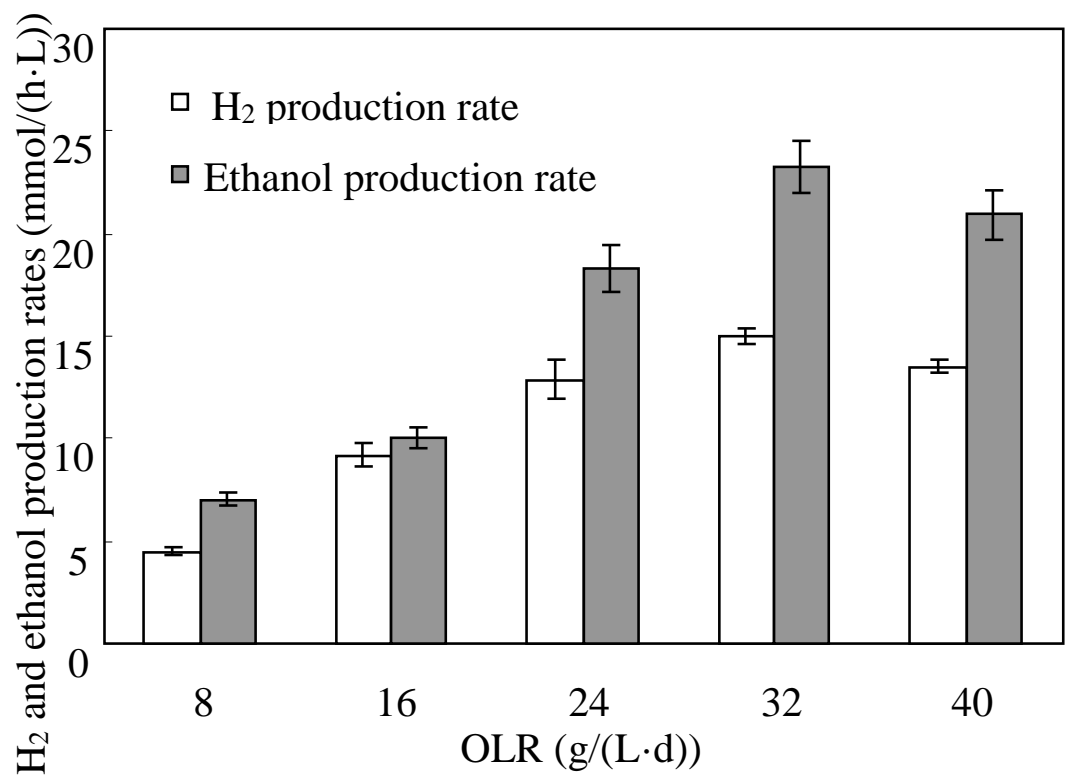

Figure 3 Performance of hydrogen and ethanol production rates at different OLRs. 


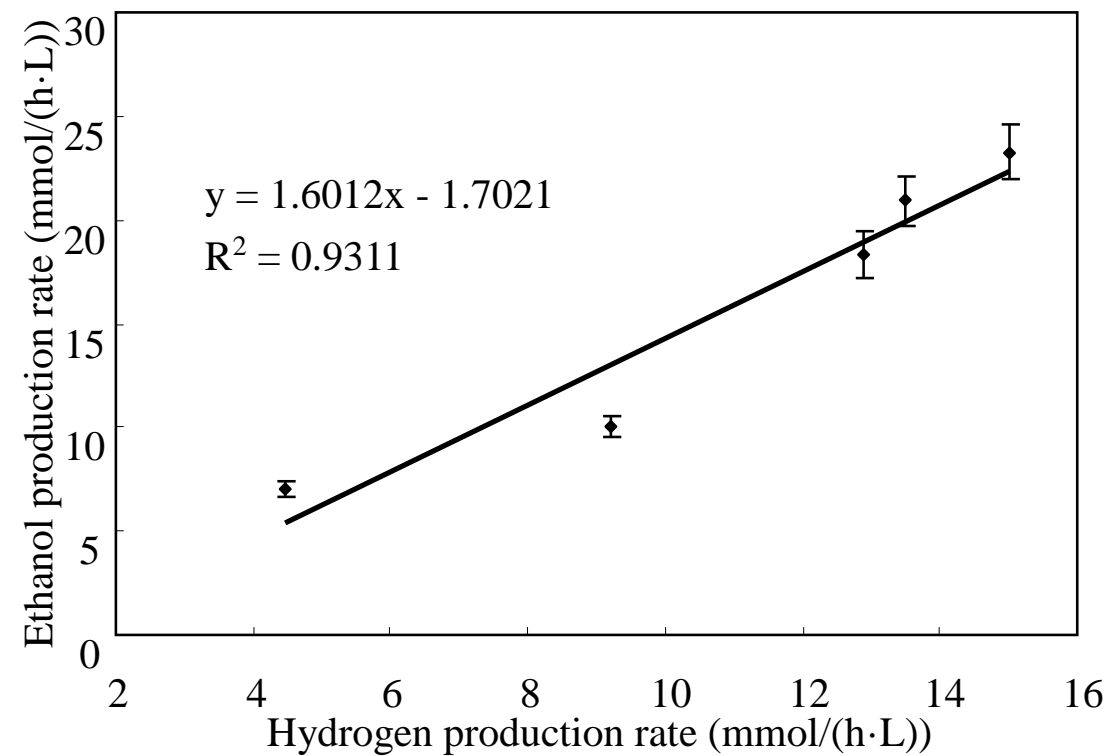

Figure 4 Correlation of hydrogen and ethanol production rates in the MPTR. 